\title{
Understanding Phase Stability of Al-Co-Cr-Fe-Ni High Entropy Alloys
}

\author{
Chuan Zhang ${ }^{1}$, Fan Zhang ${ }^{1}$, Haoyan Diao ${ }^{2}$, Michael C. Gao ${ }^{3}$, Zhi Tang $^{2}$, Jonathan D. Poplawsky ${ }^{4}$, and \\ Peter K. Liaw ${ }^{2}$ \\ ${ }^{1}$ CompuTherm LLC, 8401 Greenway Boulevard, Suite248, Middleton, WI 53562, USA \\ ${ }^{2}$ Department of Materials Science and Engineering, the University of Tennessee, Knoxville, TN 37996, USA \\ ${ }^{3}$ National Energy Technology Laboratory/AECOM, 1450 Queen Ave SW, Albany, OR 97321, USA \\ ${ }^{4}$ Center for Nanophases Materials Sciences, Oak Ridge National Laboratory, 1 Bethel Valle Rd., Oak Ridge, TN \\ 37831, USA
}

\begin{abstract}
The concept of high entropy alloy (HEA) opens a vast unexplored composition range for alloy design. As a well-studied system, Al-Co-Cr-Fe-Ni has attracted tremendous amount of attention to develop new-generation low-density structural materials for automobile and aerospace applications. In spite of intensive investigations in the past few years, the phase stability within this HEA system is still poorly understood and needs to be clarified, which poses obstacles to the discovery of promising Al-Co-CrFe-Ni HEAs. In the present work, the CALPHAD approach is employed to understand the phase stability and explore the phase transformation within the Al-Co-Cr-Fe-Ni system. The phase-stability mapping coupled with density contours is then constructed within the composition - temperature space, which provides useful guidelines for the design of low-density Al-Co-Cr-Fe-Ni HEAs with desirable properties.
\end{abstract}

\section{(I) Introduction}

Over the last decade, the concept of high entropy alloy (HEA) [1] has attracted world-wide attention for the design of novel metallic materials. HEAs contain multi-principal components $(\geq 5)$ in equal or near-equal atomic ratios and form a simple solid-solution structure, such as $b c c, f c c$, or $h c p$. This concept has revolutionized the traditional alloy design that is usually based on one or, at most two key elements, and opens a vast unexplored composition range for promising alloy design.

As one of the model HEA systems, the Al-Co-Cr-Fe-Ni HEAs have been extensively investigated in the literature [2-21]. The microstructural evolution, mechanical properties, magnetic and electrical properties, as well as oxidation resistance and anti-irradiation resistance [22] on a vast range of elemental compositions and temperatures had been reported. Despite intensive investigations, a vast 
majority of results are focused on the as-cast microstructures which are not in equilibrium. Unlike the amorphous bulk metallic glasses, which were usually used at temperatures below the glass-transition temperature $\left(\mathrm{T}_{\mathrm{g}}\right)$ and above the room temperature, the Al-Co-Cr-Fe-Ni HEAs are proposed for hightemperature applications. Thus, the thermal stability of the Al-Co-Cr-Fe-Ni HEAs is an essential factor to determine their potential properties and applications. Unfortunately, the phase stability within the Al-Co-Cr-Fe-Ni system is still poorly understood and needs to be clarified. The lack of detailed phasestability investigations has hindered the establishment of the structure-property relationship for promising alloy design in the Al-Co-Cr-Fe-Ni HEA system. The most intuitive way of representing the phase stability in a material is by its phase diagram. As the road maps of material design, phase diagrams offer the most fundamental and important information, such as the stable phases and their fractions at a given composition, for the design of new materials. Determination of phase diagrams of multi-component systems, such as HEAs, solely by experimental methods is costly and timeconsuming. On the other hand, the CALPHAD (stands for calculation of phase diagrams) approach [23-26] makes it possible to obtain multi-component phase diagrams without the need of heavy experimental work. Since the CALPHAD approach has been well established and its applications in the design of HEAs have been covered somewhere else [27-32], our scope of the present work will focus on the application of the CALPHAD approach to deeply investigate the phase stability and construct road maps for the design and development of Al-Co-Cr-Fe-Ni HEAs. In the following, we will first review the phase-equilibrium studies of the Al-Co-Cr-Fe-Ni HEAs in the literature and compare the published results with our thermodynamic predictions in Section II; We will then present phaseequilibrium investigations of the current study in order to clarify the discrepancies between experimental observations in the literature and thermodynamic predictions of the current research in Section III; We will investigate the effect of each alloying element on the phase stability and overall density in Section IV to generate a road map for the design and development of the low-density HEAs within this system; Conclusion remarks will be given in Section V.

\section{(II) Review of phase-stability studies in the literature}

The existing literature shows that the Al-Co-Cr-Fe-Ni HEA system has been extensively studied. However, vast majority results were focused on the as-cast microstructures, which is not the focus of the present work as described in the Introduction section. In this section, we will give a brief literature 
review on the limited phase-equilibrium investigations of the Al-Co-Cr-Fe-Ni system in order to understand phase stability and microstructural evolution of this system. These experimental results are summarized into two parts on the basis of their processing methodologies: the liquid metallurgy for alloys formed via melt; and the powder metallurgy for those synthesized by mechanical alloying (MA), spark plasma sintering (SPS) or direct metal deposition (DMD) process. For a better understanding, we first need to make phase names used in the different literature and the current work consistent to avoid the confusion for comparison. In this paper, the Fcc_A1 and Fcc_L1 2 are used for the disordered and ordered $f c c$ structures, respectively. Bcc_A2 is for the disordered $b c c$ structure, and Bcc_B2 is for the ordered $b c c$ structure. The $b c c$-based structure means Bcc_A2 and/or Bcc_B2.

\section{1: The liquid metallurgy}

Shun et al. [4] studied the microstructure of the $\mathrm{Al}_{0.3} \mathrm{CoCrFeNi} \mathrm{HEA}$ after isothermal aging for 72 hours at 700 and $900{ }^{\circ} \mathrm{C}$, respectively. The Fcc_A1 matrix and nano-sized platelet-shaped precipitates with an Fcc_L1 $1_{2}$ structure were found within the alloy aged at $700{ }^{\circ} \mathrm{C}$. For the alloy aged at $900{ }^{\circ} \mathrm{C}$, the Fcc_A1 and micro-sized rod-shaped Bcc_B2 phase were identified. Lin et al. [6] investigated the microstructural evolution of the $\mathrm{Al}_{0.5} \mathrm{CoCrFeNi}$ alloy annealed at five different temperatures $(350,500$, 650,800 and $950{ }^{\circ} \mathrm{C}$ ) for 24 hours individually. As increasing the aging temperature from 350 to 950 ${ }^{\circ} \mathrm{C}$, the Fcc_A1 peak intensity decreases, and the intensity of the $b c c$-based structure increases. This trend indicated that the $\mathrm{Al}_{0.5} \mathrm{CoCrFeNi} \mathrm{HEA}$ gradually transformed from an Fcc_A1 to a bcc-based structure. Kao et al. [7] prepared a series of $\mathrm{Al}_{\mathrm{x}} \mathrm{CoCrFeNi} \mathrm{HEAs}(0 \leq \mathrm{x} \leq 2)$ by arc melting and heattreated at $1100{ }^{\circ} \mathrm{C}$ for 24 hours. The structures of the alloys are single Fcc_A1 (x < 0.3), Fcc_A1 + bccbased phases $(0.3 \leq \mathrm{x} \leq 1.17)$, and $b c c$-based phases $(\mathrm{x}>1.17)$ with increasing the amount of Al. They also homogenized the $\mathrm{Al}_{0.25} \mathrm{CoCrFeNi} \mathrm{HEA}$ at $900{ }^{\circ} \mathrm{C}$ and found the Fcc_A1 + Bcc_B2 duplex structure. Wang et al. [9] studied the microstructure evolution for the $\mathrm{Al}_{\mathrm{x}} \mathrm{CoCrFeNi}_{\mathrm{HEAs}}$ (with $\mathrm{x}=0.3$, $0.5,0.7,0.9$, and 1.5$)$ aged at 900 and $1100{ }^{\circ} \mathrm{C}$ for 2 hours, respectively. Their results indicated that the $\mathrm{Al}_{0.3} \mathrm{CoCrFeNi} \mathrm{HEA}$ was a single Fcc_A1 structure, and all other alloys were Fcc_A1 + bcc-based structures at both temperatures. Tang et al. [21] investigated the phase transformation of the $\mathrm{Al}_{0.3} \mathrm{CoCrFeNi} \mathrm{HEA}$ annealed at $850{ }^{\circ} \mathrm{C}$ for one hour. The Fcc_A1 + Bcc_B2 duplex structure was confirmed by TEM analysis. 


\section{2: The powder metallurgy}

Chen et al. [8] synthesized the $\mathrm{Al}_{0.7} \mathrm{Co}_{0.3} \mathrm{CrFeNi} \mathrm{HEA}$ by MA and SPS processes. During MA, the formation of the $b c c$-based structure occurred. After SPS at $1000{ }^{\circ} \mathrm{C}$ for only 8 minutes, three phases (Fcc_A1, Bcc_A2, and Bcc_B2) were identified. Sistla et al. [12] prepared four alloys $\left(\mathrm{Al}_{1.7} \mathrm{CoCrFeNi}_{0.3}, \mathrm{AlCoCrFeNi} \mathrm{Al}_{0.7} \mathrm{CoCrFeNi}_{1.3}\right.$, and $\left.\mathrm{Al}_{0.3} \mathrm{CoCrFeNi}_{1.7}\right)$ using DMD process and annealing at $1000{ }^{\circ} \mathrm{C}$ for 100 hours. Phase-identification results using X-ray diffraction (XRD) showed duplex structures $\left(\sigma+\right.$ Bcc_B2 or Fcc_A1 + Fcc_L1 $\left.1_{2}\right)$ within these four alloys (as listed in Table 1). Fu et al. [14] prepared the $\mathrm{Al}_{0.6} \mathrm{CoCrFeNi} \mathrm{HEA}$ from powders using SPS at $1000{ }^{\circ} \mathrm{C}$ for 8 minutes or hot pressing (HP) at $1000{ }^{\circ} \mathrm{C}$ for 1 hour. The microstructures obtained using both techniques were the same Fcc_A1 + Bcc_A2 structures. Chen et al. [15] studied the $\mathrm{Al}_{0.75} \mathrm{CoCrFeNi}$ HEA sintered at $1000{ }^{\circ} \mathrm{C}$ for 8 minutes and identified the Fcc_A1 + Bcc_A2 structure using the XRD technique.

Overall, one can see that the crystal structure formation and its stability of a specific Al-Co-Cr-Fe-Ni HEA markedly depend on the alloy composition and the method of alloy preparation and post processing. Most of the alloys contain multiple phases rather than single-phase solid solutions. The phase stability of an alloy at the given temperature can also be calculated via the CALPHAD approach. Using the Pandat ${ }^{\mathrm{TM}}$ software [33] and the thermodynamic database developed in this study, the stable phases within above alloys at the according temperatures are predicted and listed in Table 1. One can see that our predicted stable phases are in good agreement with most of the experimental observations in the literature. However, there are a few discrepancies needed to be pointed out and discussed:

(a) In general, the solid-state phase transformation in the HEA is diffusion-controlled and can be rather slow. Since most of the experimental results were obtained via very short periods of heat treatments (only a few minutes or hours), the experimentally observed coexisting phases may not be in equilibrium from the thermodynamic point of view. The alloy studied in Ref. [4] aged at 700 ${ }^{\circ} \mathrm{C}$ for 72 hours contains the glamorous microstructure of Fcc_A1 + Fcc_L1 2 , while our calculation indicates to be Fcc_A1 + Bcc_B2. We doubt that annealing this alloy at $700^{\circ} \mathrm{C}$ for 72 hours may not reach equilibrium.

(b) Large discrepancies were found between our thermodynamic predications and experimental results of Ref. [12] annealed at $1000{ }^{\circ} \mathrm{C}$ for 100 hours. Those phase-equilibrium data were supposed to be more reliable than others only heat-treated for a very short time. However, the reliability of those experimental data is doubtable. Since specimens were prepared using the DMD layer by layer, the 
overall composition of these "bulk" specimens may not be homogeneous. When annealing these specimens at $1000{ }^{\circ} \mathrm{C}$ for 100 hours without any protection, vaporization of low-vapor-pressure elements (such as $\mathrm{Al}$ ) and oxidation could happen as well.

(c) Phase identifications in the literature were mostly based on the XRD results. However, it is very difficult to distinguish the co-existing phases with similar crystal structures, such as Bcc_A2 and Bcc_B2, using this technique alone. This trend is especially true when the fraction of one of the phases is tiny. The $b c c$-based structure listed in Table 1 is mainly claimed to be the disordered Bcc_A2 phase in the literature, while our calculations suggest that it should be a mixture of Bcc_A2 and Bcc_B2.

In order to clarify the above issues, phase-equilibrium investigations were carried out in the current research as well and will be discussed in Section III.

\section{(III) Experimental investigation in this study}

Five $\mathrm{Al}_{\mathrm{x}} \mathrm{CoCrFeNi}$ alloys with $\mathrm{x}=0.1,0.3,0.5,0.7$, and 1.0 were fabricated and treated with hot isostatic pressing (HIP) at $1250{ }^{\circ} \mathrm{C}$ for 50 hours. Their chemical compositions were analyzed using inductively coupled plasma mass spectrometry (ICP-MS). The measured compositions are very close to our nominal compositions. Then small pieces of specimens cut from these alloys were wrapped with tantalum foil and sealed in a quartz tube backed filled with the argon atmosphere to go through various heat treatments. In addition to the XRD, optical microscopy (OM), scanning electron microscopy (SEM), and electron backscatter diffraction (EBSD) techniques, the atom probe tomography (APT) was also used in the present work to distinguish the similar phases. More details on the experiments can be found in other reports $[19,34,35]$. Only two critical experimental results will be discussed below to verify our thermodynamic predictions and clarify issues mentioned in Section II.

\section{1: The $\mathrm{Al}_{0.3} \mathrm{CoCrFeNi}$ alloy}

Figure 1(a) shows the equilibrium calculation for the $\mathrm{Al}_{0.3} \mathrm{CoCrFeNi}$ alloy of the current work. One can see that its melting temperature is about $1405{ }^{\circ} \mathrm{C}$. At the temperature range from 1028 to $1405{ }^{\circ} \mathrm{C}$, Fcc_A1 is the only stable phase. Below $1028{ }^{\circ} \mathrm{C}$, the ordered Bcc_B2 phase (originated from the AlNi binary phase) will precipitate out from the Fcc_A1 matrix. At even lower temperatures, other phases (such as $\sigma$ ) will form. In this study, the $\mathrm{Al}_{0.3} \mathrm{CoCrFeNi} \mathrm{HIPed}$ at $1250{ }^{\circ} \mathrm{C}$ for 50 hours contains the Fcc_A1 phase only. In order to clarify the discrepancies between our calculation and experimental 
observations of [4] at $700{ }^{\circ} \mathrm{C}$, the HIPed specimens were then heat-treated at $700{ }^{\circ} \mathrm{C}$ for $50,100,200$, and 500 hours, respectively. Only the Fcc_A1 phase was observed within the samples for 50 and 100 hours, while the nano-sized Bcc_B2 phase precipitated out from the Fcc_A1 matrix in the sample aged for 200 hours. The phases coexisting in the sample heat-treated for 500 hours are the same as that for 200 hours, but the size of the Bcc_B2 phase is much greater due to the coarsening (as shown in Figure 1(b)). The APT measured composition of the Fcc_A1 matrix is about $5 \mathrm{Al}, 26 \mathrm{Co}, 26 \mathrm{Cr}, 25 \mathrm{Fe}, 18 \mathrm{Ni}$ (at.\%) and that of the Bcc_B2 phase is around 37Al, $12 \mathrm{Co}, 2 \mathrm{Cr}, 7 \mathrm{Fe}$, and $42 \mathrm{Ni}$ (at.\%). Our experimental results clearly indicate that long-period ageing is necessary for the Al-Co-Cr-Fe-Ni HEAs to reach equilibrium especially at lower temperatures.

\section{2: The $\mathrm{Al}_{0.7} \mathrm{CoCrFeNi}$ alloy}

Figure 2(a) shows the equilibrium calculation for the $\mathrm{Al}_{0.7} \mathrm{CoCrFeNi}$ alloy of the present work. The calculated melting temperature of this alloy is about $1340{ }^{\circ} \mathrm{C}$, which is $65{ }^{\circ} \mathrm{C}$ lower than that of the $\mathrm{Al}_{0.3} \mathrm{CoCrFeNi}$ alloy. The Fcc_A1, Bcc_B2 and Bcc_A2 phases coexist at the temperature range between 880 and $1340^{\circ} \mathrm{C}$. The fraction of the Bcc_B2 phase increases with decreasing temperatures. While the fraction of Fcc_A1 phase decreases when reducing temperature. Below $880{ }^{\circ} \mathrm{C}$, the disordered Bcc_A2 phase disappears and the $\sigma$ phase precipitates out from the Fcc_A1 matrix. Figure 2(b) and (c) show the microstructure of the $\mathrm{Al}_{0.7} \mathrm{CoCrFeNi}$ alloy homogenized at $1250{ }^{\circ} \mathrm{C}$ for 50 and 1000 hours, respectively. One can see the laminar morphology phases within the specimen after ageing for 50 hours, and two distinguished phase coexist within the specimen heat-treated at $1250{ }^{\circ} \mathrm{C}$ for 1000 hours. Both specimens could be in equilibrium and the phase morphology changing from laminar to blocky is due to coarsening effect. As shown in Figure 2(c), Phase-identification results indicate that the grey phase is Fcc_A1 and the dark one is Bcc_B2. While there are three phases, Fcc_A1 ( 80\%), Bcc_B2 ( 18\%), and Bcc_A2 ( 2\%), on the basis of our prediction as shown in Figure 2(a). Due to the tiny amount of Bcc_A2 and a similar crystal structure with Bcc_B2, it will be very challenging to distinguish the Bcc_A2 phase via XRD or SEM. Therefore, APT was used in the current work to verify the equilibrium phases within this alloy homogenized at $1250{ }^{\circ} \mathrm{C}$ for 1000 hours (as shown in Figure 2(d)). The top part of Figure 2(d) indicates that only one phase exists within the grey phase (Fcc_A1) region of Figure 2(c). While the bottom part of Figure 2(d) clearly shows that there are two different phases rather than one within the dark phase ("Bcc_B2") region of Figure 2(c). For phase 
identification, the compositions of these two phases were also measured by the APT. The matrix phase contains $\mathrm{Al}(\sim 30$ at.\%), Ni-rich ( 34 at.\%), Fe ( 14 at.\%), and Co ( 20 at.\%), which is identified to be the ordered Bcc_B2 phase. And the other one is a Cr-rich ( 86at.\%) Bcc_A2 phase with Fe $(\sim 7$ at.\%) and Co $(\sim 7$ at. \%). The identified phases agree well with our thermodynamic prediction.

Using the critical experimental results of this study as discussed above, we have clarified the discrepancies between our thermodynamic predictions and experimental observations in the literature as listed in Table 1 and have verified the reliability of our thermodynamic predictions. Next, we are going to take advantage of thermodynamic calculations to understand the effect of each alloying element on the phase stability and establish a road map for the design and development of the lowdensity Al-Co-Cr-Fe-Ni HEAs.

\section{(IV) Phase-stability mapping via thermodynamic calculations}

Taking the advantage of the CALPHAD method, several types of phase diagrams will be calculated, such as the three-dimensional (3D) phase projection, isopleth, and isothermal section. The density contours were also superimposed on the calculated phase diagrams.

\section{1: 3D single Fcc_A1 phase projection}

Figure 3 shows the 3D projection of the Fcc_A1 phase within the spaces of Ni-Co-Fe, Ni-Co-Cr, and Ni-Co-Al ternary systems above $700{ }^{\circ} \mathrm{C}$, respectively. As shown in Figure 3(a), the Fcc_A1 phase occupies almost the entire space of the Ni-Co-Fe ternary system. Other phases only exist at the Fe-rich corner. When replacing Fe with Cr, the Fcc_A1 phase within the Ni-Co-Cr ternary system was reduced to the region of $\mathrm{x}(\mathrm{Cr})<50$ at.\% (as shown in Figure 3(b)). Figure 3(c) indicates that $\mathrm{Al}$ has a stronger effect than Cr to destabilize the Fcc_A1 phase. The Fcc_A1 phase region was squeezed to the region of $\mathrm{x}(\mathrm{Al})<10$ at.\% within the Ni-Co-Al ternary system. In fact, the 3D phase projections for all constituent ternaries of the Al-Co-Cr-Fe-Ni quinary system are calculated. But only three typical ones are shown in Figure 3 in order to save space. These 3D phase projections give us an overall picture of the effect of each element on the stability of the Fcc_A1 phase within a large temperature range $(>700$ $\left.{ }^{\circ} \mathrm{C}\right)$. Co and Ni are Fcc_A1 phase stabilizers. Fe plays a neutral role while the others, especially Al, destabilize the Fcc_A1 phase. 
Unfortunately, the 3D phase projection is limited to a ternary system for visualization. In order to study the effect of alloying elements on the phase stabilities of higher-order systems within large temperature ranges, one can use the calculated isopleths as shown in the following section.

\section{2: Isopleths to exploring effect of alloying elements}

Isopleth is a temperature-concentration phase diagram of a ternary or higher order system, which is a vertical two-dimensional (2D) section with temperature as one axis, and composition as the other. In this study, several isopleths are calculated in order to investigate the effect of $\mathrm{Al}$ addition on the phase stability of the Al-Co-Cr-Fe-Ni HEAs. Since the density of these HEAs is also very important for their potential applications, the density contours are also superimposed in the calculated phase diagrams.

Figure 4(a) shows the calculated isopleth of $\mathrm{Al}_{\mathrm{x}} \mathrm{CoFeNi}$. As is seen, the CoFeNi alloy (when $\mathrm{x}=0$ ) is a single Fcc_A1 phase from low temperature up to the melting temperature. The addition of Al promotes the formation of Bcc_B2 and destabilizes the Fcc_A1 phase, especially at lower temperatures. When keeping the $\mathrm{Co}, \mathrm{Fe}$, and $\mathrm{Ni}$ at an equal atomic ratio of 1 , the maximum $\mathrm{Al}$ ratio reduces from $\sim 0.6$ to 0.2 to maintain the single Fcc_A1 from $\sim 1400$ to $700{ }^{\circ} \mathrm{C}$. On the basis of the calculated density contour in the same diagram, there is no surprise that more $\mathrm{Al}$ addition will decrease the overall density from $\sim 8.2$ to $6.7 \mathrm{~g} / \mathrm{cm}^{3}$. Note that the densities of HEAs reported in literature were usually estimated by mixing the density of each component at room temperature, which is misleading and inaccurate. First of all, the density of an element is function of both the temperature and crystal structure. Second, if the HEAs contain more than one phase, the densities of different phases are different as well. The CALPHAD approach can be used to develop the corresponding molar volume database using the approach presented by Lu et al. [36]. In brief, the molar volume of element i with crystal structure $\varphi$ can be expressed as:

$V_{i}^{\varphi}(T)=V_{0} \exp \left(\int_{T_{0}}^{T} 3 \alpha d T\right)$

where $\mathrm{V}_{0}$ is the molar volume under atmospheric pressure at the reference temperature $\mathrm{T}_{0}$. And $\alpha$ is the coefficient of linear thermal expansion (CLE). The volume of a phase with crystal structure $\varphi$ can then be obtained via the Redlich-Kister polynomial [37]: 
$V^{\varphi}(T)=\sum_{i} x_{i} V_{i}^{\varphi}+V_{m}^{e x}$

where $\mathrm{x}_{\mathrm{i}}$ is the mole fraction of element $\mathrm{i}$ and $V_{m}^{e x}$ is the excess molar volume. Using ternary system as an example, the $V_{m}^{e x}$ can be expressed by:

$V_{m}^{e x}=\sum_{i \neq j} x_{i} x_{j} L_{i, j}^{\varphi}+x_{i} x_{j} x_{k} L_{i, j, k}^{\varphi}$

The terms $L_{i, j}^{\varphi}$ and $L_{i, j, k}^{\varphi}$ are the interaction parameters from the constituent binary and the ternary systems, respectively.

The molar volume database enables us to calculate the density based on the relationship of $\rho=M / V_{m}$ ( $\rho$ is the mass density, $M$ is the molar mass, and $V_{m}$ is the molar volume). In this study, the corresponding molar volume database was developed considering molar volumes of all existing phases presented in our calculated phase diagrams. Figure 4(b) shows the calculated isopleth of $\mathrm{Al}_{x} \mathrm{CoCrFeNi}$ and a similar tendency was found for $\mathrm{Al}$ addition. It also indicates that the addition of $\mathrm{Cr}$ stabilizes the disordered Bcc_A2 phase rather than ordered Bcc_B2. The maximum Al ratio changes from $\sim 0.5$ to 0.1 to keep the single Fcc_A1 phase from 1350 to $700{ }^{\circ} \mathrm{C}$ with $\mathrm{Co}, \mathrm{Cr}, \mathrm{Fe}$, and $\mathrm{Ni}$ at the equal atomic ratio of 1 . It should point out that phase diagrams with density contour lines allow users to quickly identify the optimum alloy compositions which satisfy both the phase stability and density requirements.

In order to further explore the effect of each alloying element, the isopleths with non-equal-atomic ratios of other elements $(\mathrm{Co}, \mathrm{Cr}, \mathrm{Fe}$, and $\mathrm{Ni}$ ) are also calculated and shown in Figure 5. By comparing Figure 5(a) with Figure 4(b), it is obvious that a higher Co content will stabilize Fcc_A1. On the other hand, adding more Co is unfavorable to the density requirement. A similar effect was found for more $\mathrm{Ni}$ addition, as shown in Figure 5(c). Due to the neutral effect of Fe on both Bcc_A2 and Fcc_A1, the Fe addition makes the Bcc_A2 phase more stable than the Bcc_B2 phase in the higher Al region without destabilizing the Fcc_A1 phase in the lower Al region (as indicated in Figure 5(d)). A higher $\mathrm{Fe}$ content will certainly increase the density due to the higher density of Fe. With a higher ratio of $\mathrm{Cr}$, the stable region of the Fcc_A1 phase was significantly reduced especially at lower temperatures, and the disordered Bcc_A2 phase becomes more stable. 
The isopleths shown in Figures 4 and 5 are very useful to demonstrate the effect of each component on the phase stability and density of the Al-Co-Cr-Fe-Ni HEAs at varying temperatures. Another useful type of $2 \mathrm{D}$ diagrams is the isothermal section from which we can understand the effects of two components at a fixed temperature. In the following part, we will use the calculated isothermal sections coupled with density contour to further understand the effects of alloying elements on the phase stability and density of the Al-Co-Cr-Fe-Ni HEAs.

\section{3: Isothermal sections to exploring effect of alloying elements}

Isothermal section is a phase diagram of a ternary or higher order system with all points on the section are at the same temperature, which is a representation of the stable phases for different compositions at this fixed temperature. In this study, two isothermal sections coupled with density contours are calculated at $1000^{\circ} \mathrm{C}$ as examples.

Figure 6(a) shows the calculated isothermal section of $\mathrm{Al}-\mathrm{Co}-\mathrm{Ni}-20 \mathrm{Cr}-20 \mathrm{Fe}$ (at.\%) at $1000{ }^{\circ} \mathrm{C}$. In this phase diagram, the compositions of $\mathrm{Cr}$ and $\mathrm{Fe}$ are both fixed at 20 at.\%, while the compositions of the other three components vary in the Gibbs triangle. The composition at the original corner is $60 \mathrm{Ni}-20 \mathrm{Cr}-$ 20Fe (at.\%). $\mathrm{X}$ and $\mathrm{Y}$ axes indicate the composition-change by replacing $\mathrm{Ni}$ with Co and $\mathrm{Al}$, respectively. As one can see from this figure, the calculated phase boundaries are roughly parallel to the Co-Ni-rich side, which indicates that the $\mathrm{Co}$ and $\mathrm{Ni}$ can exchange with each other and the phase transformations are mainly determined by the addition of $\mathrm{Al}$. When $\mathrm{x}(\mathrm{Al})<\sim 10$ at.\%, one can obtain the Fcc_A1 single-phase region. When $\mathrm{x}(\mathrm{Al})>\sim 23$ at.\%, there will be no more Fcc_A1 phase. In addition to the calculated phase boundaries, the contour lines of the overall density (red lines) are superimposed on the same plot as well. Due to the similarity between the densities of Co and $\mathrm{Ni}$, the change of overall density mainly occurs with the addition of $\mathrm{Al}$ (along the $\mathrm{Y}$ axis). Figure 6(b) shows the calculated isothermal section of $\mathrm{Al}-\mathrm{Cr}-\mathrm{Fe}-20 \mathrm{Co}-20 \mathrm{Ni}\left(\right.$ at.\%) at $1000{ }^{\circ} \mathrm{C}$. The composition at the original corner is $60 \mathrm{Cr}-20 \mathrm{Co}-20 \mathrm{Ni}$ (at.\%). $\mathrm{X}$ and $\mathrm{Y}$ axes indicate the composition-change by replacing $\mathrm{Cr}$ with $\mathrm{Fe}$ and $\mathrm{Al}$, respectively. The $\sigma$ phase originated from the $\mathrm{Co}-\mathrm{Cr}$ binary system was found at the Cr-rich corner. With the addition of Fe along the X axis, the Fcc_A1 single-phase region formed at the Fe-rich region. The bcc-based structure becomes more stable with the addition of $\mathrm{Al}$ (along the Y axis). Since the densities of $\mathrm{Cr}$ and $\mathrm{Fe}$ are close to each other, the overall density variation is mainly determined by the $\mathrm{Al}$ content. 
Here we would like to emphasize that all calculations of this work are a few examples to give an overview picture of the phase stability within the Al-Co-Cr-Fe-Ni system. Taking advantage of the modern computational-thermodynamics tool and proper databases, one can explore every single point within multi-component systems for potential HEAs with derisible microstructures.

\section{(V) Conclusion and outlook}

The concept of HEA opens the vast unexplored compositional space for the design and development of new alloys. It is almost impossible and extremely challenging to use the trial and error approach for the discovery of new HEAs. Thus, computational approaches are urgently needed that can guide design and accelerate the development of HEAs with promising properties. In the present work, phase diagram calculation by the CALPHAD approach is used for such a purpose. Phase stability of the Al-Co-Cr-FeNi system was studied by integrating phase-diagram calculation with key experimental investigations. The results are summarized as follows:

(a): The discrepancies found between the calculations and experimental observations were explained. Long periods of heat treatments are necessary for the Al-Co-Cr-Fe-Ni alloys to reach equilibrium especially at lower temperatures. Additional efforts should be used in phase identification, especially when there are two phases with similar crystal structures and one with a small volume fraction.

(b): Both Co and Ni are found to be Fcc_A1 stabilizers, while Fe has a neutral effect on both the Fcc_A1 and Bcc_A2 phases. Cr stabilizes the Bcc_A2 phase, and Al is a strong stabilizer for the ordered Bcc_B2 phase.

(c): Calculated isopleths with density contours provide useful guidelines for the design of low-density single-phase (Fcc_A1) HEAs within the Al-Co-Cr-Fe-Ni system.

(d): The calculated isothermal sections at $1000{ }^{\circ} \mathrm{C}$ with density contours demonstrate the effects of alloying elements on both the phase stability and density of the Al-Co-Cr-Fe-Ni HEAs at this temperature.

The CALPHAD approach has been proved to be very useful for the design and development of HEAs. In order to use the CALPHAD approach, both the software and databases are necessary. The current challenge is the development of reliable multi-component thermodynamic databases suitable for the design and search of HEAs. Unlike traditional thermodynamic databases, which only focus on the 
corner of one or two principal components, thermodynamic databases for HEAs are required to cover the entire composition range. Thus, a tremendous amount of modeling work and reliable thermochemical and/or phase-equilibrium data are needed. However, the reliable phase equilibria are very limited as summarized in the literature review part. Team work is needed to accelerate the development of new HEAs, which requires the HEA community to reach a consensus and make common efforts.

The novel scope of CALPHAD has broadened beyond phase diagrams to include thermophysical and kinetic properties. Thermodynamic calculation and kinetic simulations using the CALPHAD based modeling tools have become an essential part of modern materials design. Of course, the material properties are far more complex to be predicted from one single modeling method at present, but CALPHAD is the fundamental one to start with. Other modeling tools, when integrated under the framework of Integrated Computational Materials Engineering (ICME) and combined with key experiments, make the materials design process much more focused and cost-efficient [38].

Acknowledgments: The authors very much appreciate the finical support from the U.S. Army Office Project (W911NF-13-1-0438), and US Department of Energy (DOE) Office of Fossil Energy, National Energy Technology Laboratory (NETL) (DE-FE-0008855 and DE-FE-0024054). M.C.G. acknowledges the support by the Cross-Cutting Technologies Program at NETL under the RES contract DE-FE-0004000. APT was conducted at ORNL's Center for Nanophase Materials Sciences (CNMS), which is a U.S. DOE Office of Science User Facility. U.S. DOE Office of Science User Facility. 
Table 1: Equilibrium microstructure comparison between experimental observations and thermodynamic predictions

\begin{tabular}{|c|c|c|c|c|}
\hline \multirow{2}{*}{ Alloys } & \multirow{2}{*}{$\begin{array}{l}\text { Heat-treatment } \\
\text { Condition }\end{array}$} & \multirow{2}{*}{$\begin{array}{l}\text { Synthesis } \\
\text { methodology }\end{array}$} & \multicolumn{2}{|c|}{ Equilibrium Phases } \\
\hline & & & Experiment & Calculation of this work \\
\hline $\mathrm{Al}_{0.3} \mathrm{CoCrFeNi}[4]$ & $\begin{array}{c}\text { Aged at } 700{ }^{\circ} \mathrm{C} \text { for } 72 \\
\text { hours }\end{array}$ & LM & Fcc_A1 + Fcc_L1 $1_{2}$ & Fcc_A1 + Bcc_B2 \\
\hline $\mathrm{Al}_{0.3} \mathrm{CoCrFeNi}[4]$ & $\begin{array}{c}\text { Aged at } 900{ }^{\circ} \mathrm{C} \text { for } 72 \\
\text { hours }\end{array}$ & LM & Fcc_A1 + Bcc_B2 & Fcc_A1 + Bcc_B2 \\
\hline $\mathrm{Al}_{0.5} \mathrm{CoCrFeNi}[6]$ & $\begin{array}{c}\text { Aged at } 950{ }^{\circ} \mathrm{C} \text { for } 24 \\
\text { hours }\end{array}$ & LM & Fcc_A $1+b c c$-based structure & Fcc_A1 + Bcc_B2 \\
\hline $\mathrm{Al}_{0.25} \mathrm{CoCrFeNi}[7]$ & Aged at $900^{\circ} \mathrm{C}$ & LM & Fcc_A1 + Bcc_B2 & Fcc_A1 + Bcc_B2 \\
\hline $\mathrm{Al}_{0.25} \mathrm{CoCrFeNi}[7]$ & $\begin{array}{c}\text { Aged at } 1100{ }^{\circ} \mathrm{C} \text { for } 24 \\
\text { hours }\end{array}$ & LM & Fcc_A1 & Fcc_A1 \\
\hline $\mathrm{Al}_{0.375} \mathrm{CoCrFeNi}[7]$ & \multirow{5}{*}{$\begin{array}{c}\text { Aged at } 1100^{\circ} \mathrm{C} \text { for } 24 \\
\text { hours }\end{array}$} & \multirow{5}{*}{ LM } & \multirow{5}{*}{ Fcc_A1 + bcc-based structure } & Fcc_A1 + Bcc_A2 +Bcc_B2 \\
\hline $\mathrm{Al}_{0.5} \mathrm{CoCrFeNi}[7]$ & & & & Fcc_A1 + Bcc_A $2+$ Bcc_B2 \\
\hline $\mathrm{Al}_{0.75} \mathrm{CoCrFeNi}[7]$ & & & & Fcc_A1 + Bcc_A2 +Bcc_B2 \\
\hline $\mathrm{Al}_{0.875} \mathrm{CoCrFeNi}$ [7] & & & & Fcc_A1 + Bcc_A2 +Bcc_B2 \\
\hline $\mathrm{Al}_{1.0} \mathrm{CoCrFeNi}[7]$ & & & & Fcc_A1 + Bcc_A2 +Bcc_B2 \\
\hline $\mathrm{Al}_{1.25} \mathrm{CoCrFeNi}[7]$ & \multirow{3}{*}{$\begin{array}{c}\text { Aged at } 1100{ }^{\circ} \mathrm{C} \text { for } 24 \\
\text { hours }\end{array}$} & \multirow{3}{*}{ LM } & \multirow{3}{*}{$b c c$-based structure } & Bcc_A2 +Bcc_B2 \\
\hline $\mathrm{Al}_{1.5} \mathrm{CoCrFeNi}[7]$ & & & & Bcc_A2 +Bcc_B2 \\
\hline $\mathrm{Al}_{2.0} \mathrm{CoCrFeNi}[7]$ & & & & Bcc_A2 +Bcc_B2 \\
\hline $\mathrm{Al}_{0.7} \mathrm{Co}_{0.3} \mathrm{CrFeNi}[8]$ & $\begin{array}{c}\text { Aged at } 1000{ }^{\circ} \mathrm{C} \text { for } 8 \\
\text { minutes }\end{array}$ & SPS & Fcc_A1 + Bcc_A2+Bcc_B2 & Fcc_A1 + Bcc_A2 +Bcc_B2 \\
\hline \multirow{2}{*}{$\mathrm{Al}_{0.3} \mathrm{CoCrFeNi}[9]$} & $\begin{array}{c}\text { Aged at } 900{ }^{\circ} \mathrm{C} \text { for } 2 \\
\text { hours }\end{array}$ & LM & \multirow{2}{*}{ Fcc_A1 } & \multirow{2}{*}{ Fcc_A1 } \\
\hline & $\begin{array}{c}\text { Aged at } 1100^{\circ} \mathrm{C} \text { for } 2 \\
\text { hours }\end{array}$ & LM & & \\
\hline \multirow{2}{*}{$\mathrm{Al}_{0.5} \mathrm{CoCrFeNi}[9]$} & $\begin{array}{c}\text { Aged at } 900{ }^{\circ} \mathrm{C} \text { for } 2 \\
\text { hours }\end{array}$ & $\mathrm{LM}$ & \multirow{2}{*}{ Fcc_A1 + bcc-based structure } & \multirow{2}{*}{ Fcc_A1 + Bcc_B2 } \\
\hline & $\begin{array}{c}\text { Aged at } 1100^{\circ} \mathrm{C} \text { for } 2 \\
\text { hours }\end{array}$ & LM & & \\
\hline \multirow{2}{*}{$\mathrm{Al}_{0.7} \mathrm{CoCrFeNi}[9]$} & $\begin{array}{c}\text { Aged at } 900{ }^{\circ} \mathrm{C} \text { for } 2 \\
\text { hours }\end{array}$ & LM & \multirow{2}{*}{ Fcc_A1 + Bcc_B2 } & \multirow{2}{*}{ Fcc_A1 + Bcc_A2 +Bcc_B2 } \\
\hline & $\begin{array}{c}\text { Aged at } 1100^{\circ} \mathrm{C} \text { for } 2 \\
\text { hours }\end{array}$ & LM & & \\
\hline \multirow{2}{*}{$\mathrm{Al}_{0.9} \mathrm{CoCrFeNi}[9]$} & $\begin{array}{c}\text { Aged at } 900{ }^{\circ} \mathrm{C} \text { for } 2 \\
\text { hours }\end{array}$ & LM & \multirow{2}{*}{ Fcc_A1 + Bcc_B2 } & \multirow{2}{*}{ Fcc_A1 + Bcc_A2 +Bcc_B2 } \\
\hline & $\begin{array}{c}\text { Aged at } 1100^{\circ} \mathrm{C} \text { for } 2 \\
\text { hours }\end{array}$ & LM & & \\
\hline $\mathrm{Al}_{1.5} \mathrm{CoCrFeNi}[9]$ & $\begin{array}{c}\text { Aged at } 900{ }^{\circ} \mathrm{C} \text { for } 2 \\
\text { hours }\end{array}$ & $\mathrm{LM}$ & Bcc_A2 + Bcc_B2 & Bcc_A2 + Bcc_B2 \\
\hline
\end{tabular}




\begin{tabular}{|c|c|c|c|c|}
\hline & $\begin{array}{c}\text { Aged at } 1100{ }^{\circ} \mathrm{C} \text { for } 2 \\
\text { hours }\end{array}$ & LM & & \\
\hline $\begin{array}{c}\mathrm{Al}_{1.7} \mathrm{CoCrFeNi}_{0.3} \\
{[12]}\end{array}$ & \multirow{4}{*}{$\begin{array}{c}\text { Aged at } 1000^{\circ} \mathrm{C} \text { for } 100 \\
\text { hours }\end{array}$} & \multirow{4}{*}{ DMD } & $\sigma+$ Bcc_B2 & Bcc_A2 + Bcc_B2 \\
\hline $\mathrm{Al}_{1.0} \mathrm{CoCrFeNi}[12]$ & & & $\sigma+$ Bcc_B2 & Fcc_A1 + Bcc_A2 +Bcc_B2 \\
\hline $\begin{array}{c}\mathrm{Al}_{0.7} \mathrm{CoCrFeNi} i_{1.3} \\
{[12]}\end{array}$ & & & Fcc_A1 + Fcc_L1 $1_{2}$ & Fcc_A1 + Bcc_B2 \\
\hline $\begin{array}{c}\mathrm{Al}_{0.3} \mathrm{CoCrFeNi}_{1.7} \\
{[12]}\end{array}$ & & & Fcc_A1 + Fcc_L1 $1_{2}$ & Fcc_A1 \\
\hline $\mathrm{Al}_{0.6} \mathrm{CoCrFeNi}[14]$ & $\begin{array}{l}\text { Aged at } 1000^{\circ} \mathrm{C} \text { for } 8 \\
\text { minutes or } \mathrm{HP} \text { at } 1000 \\
{ }^{\circ} \mathrm{C} \text { for } 1 \text { hour }\end{array}$ & SPS & Fcc_A1 + Bcc_A2 & Fcc_A1 + Bcc_A2 +Bcc_B2 \\
\hline $\mathrm{Al}_{0.75} \mathrm{CoCrFeNi}[15]$ & $\begin{array}{c}\text { Aged at } 1000{ }^{\circ} \mathrm{C} \text { for } 8 \\
\text { minutes }\end{array}$ & SPS & Fcc_A1 + Bcc_A2 & Fcc_A1 + Bcc_A2 +Bcc_B2 \\
\hline $\mathrm{Al}_{0.3} \mathrm{CoCrFeNi}[21]$ & $\begin{array}{c}\text { Aged at } 850{ }^{\circ} \mathrm{C} \text { for } 1 \\
\text { hour }\end{array}$ & LM & Fcc_A1 + Bcc_B2 & Fcc_A1 + Bcc_B2 \\
\hline
\end{tabular}

*LM - liquid metallurgy; MA - mechanical alloying, SPS - spark plasma sintering; DMD- direct metal deposition 

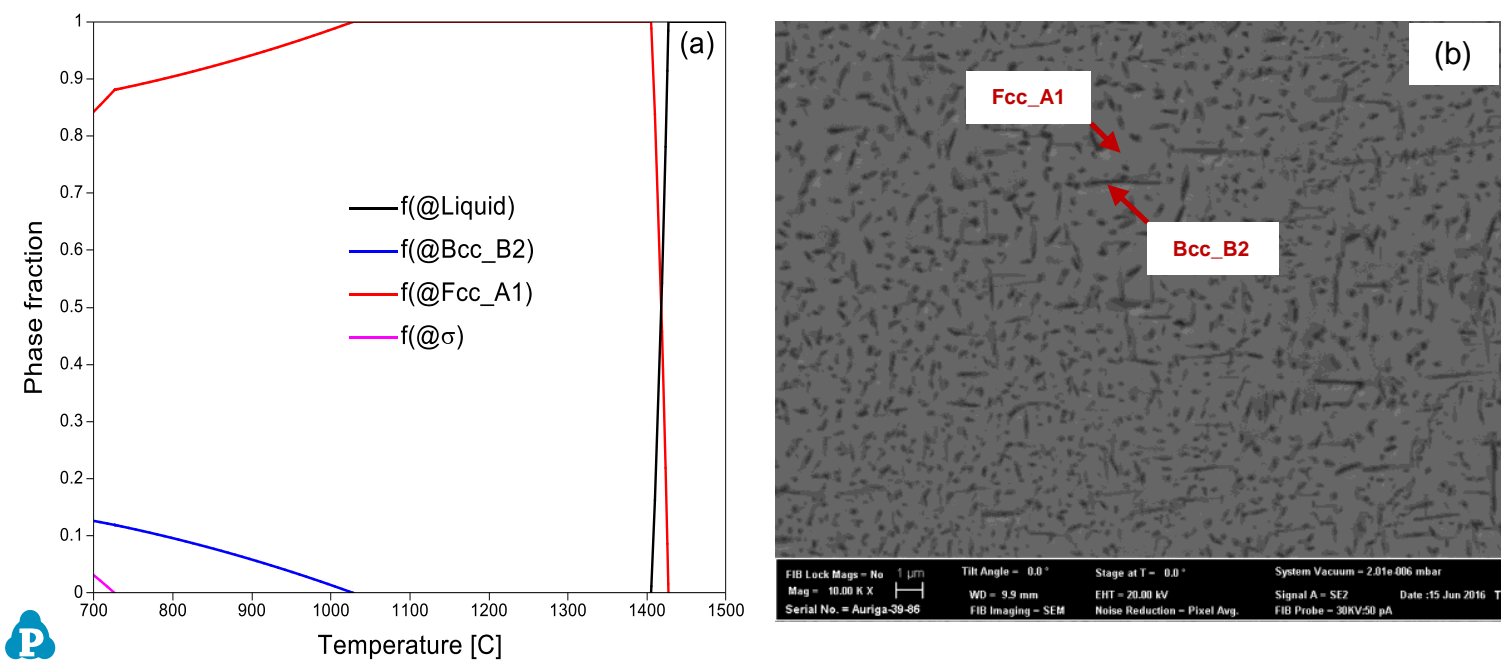

Figure 1: Comparison between the calculation and experimental observation of $\mathrm{Al}_{0.3} \mathrm{CoCrFeNi} \mathrm{HEA}$ (a) Equilibrium calculation; (b) SEM image of speciment aged at $700{ }^{\circ} \mathrm{C}$ for 500 hours
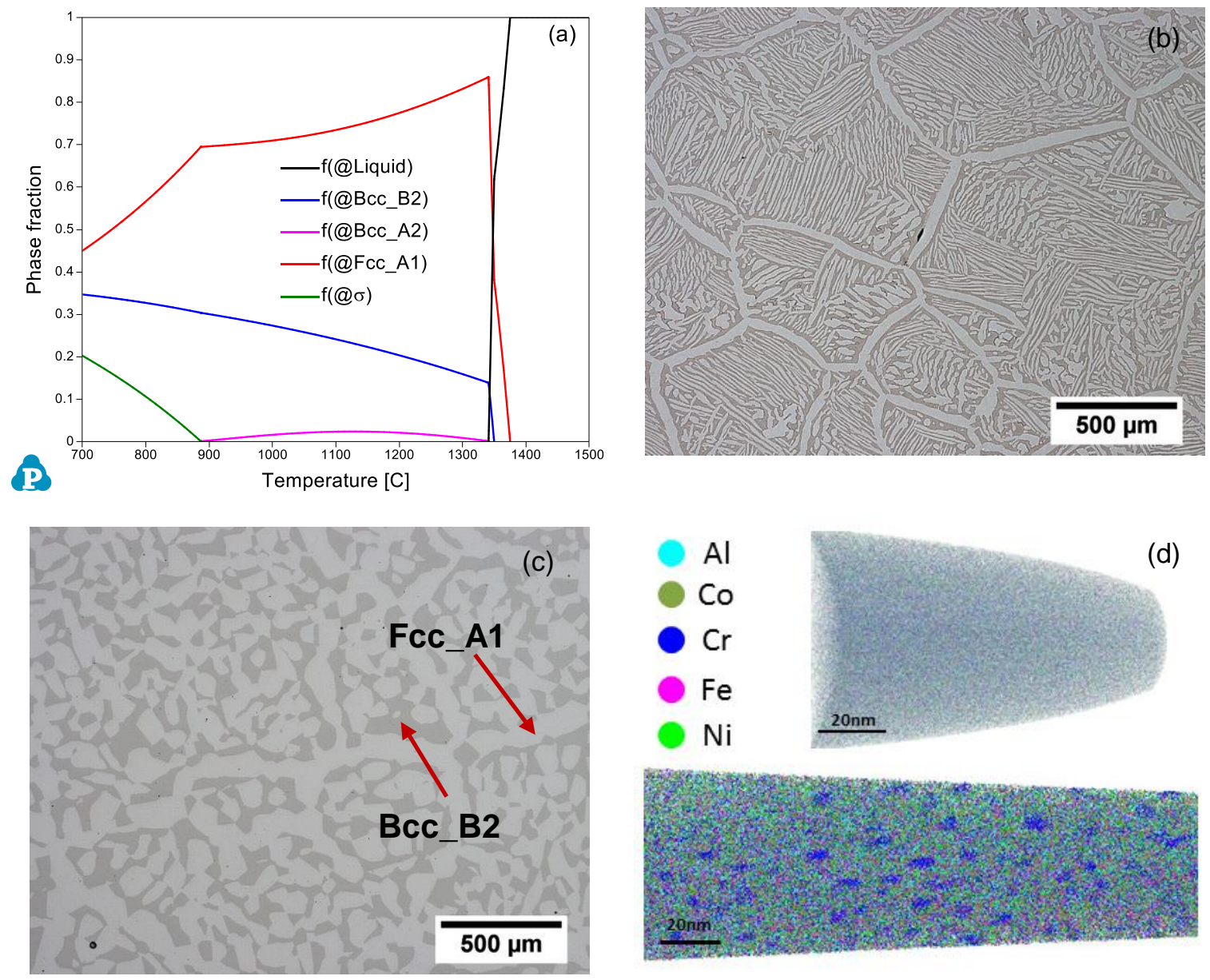

(d)

Figure 2: Comparison between the calculation and experimental observation of $\mathrm{Al}_{0.7} \mathrm{CoCrFeNi} \mathrm{HEA}$ (a) Equilibrium calculation; (b) OM image of speciment aged at $1250{ }^{\circ} \mathrm{C}$ for 50 hours; (c) OM image of speciment aged at $1250^{\circ} \mathrm{C}$ for 1000 hours; (d) APT results: Fcc_A1 (top), Bcc_A2 + Bcc_B2 (bottom) 

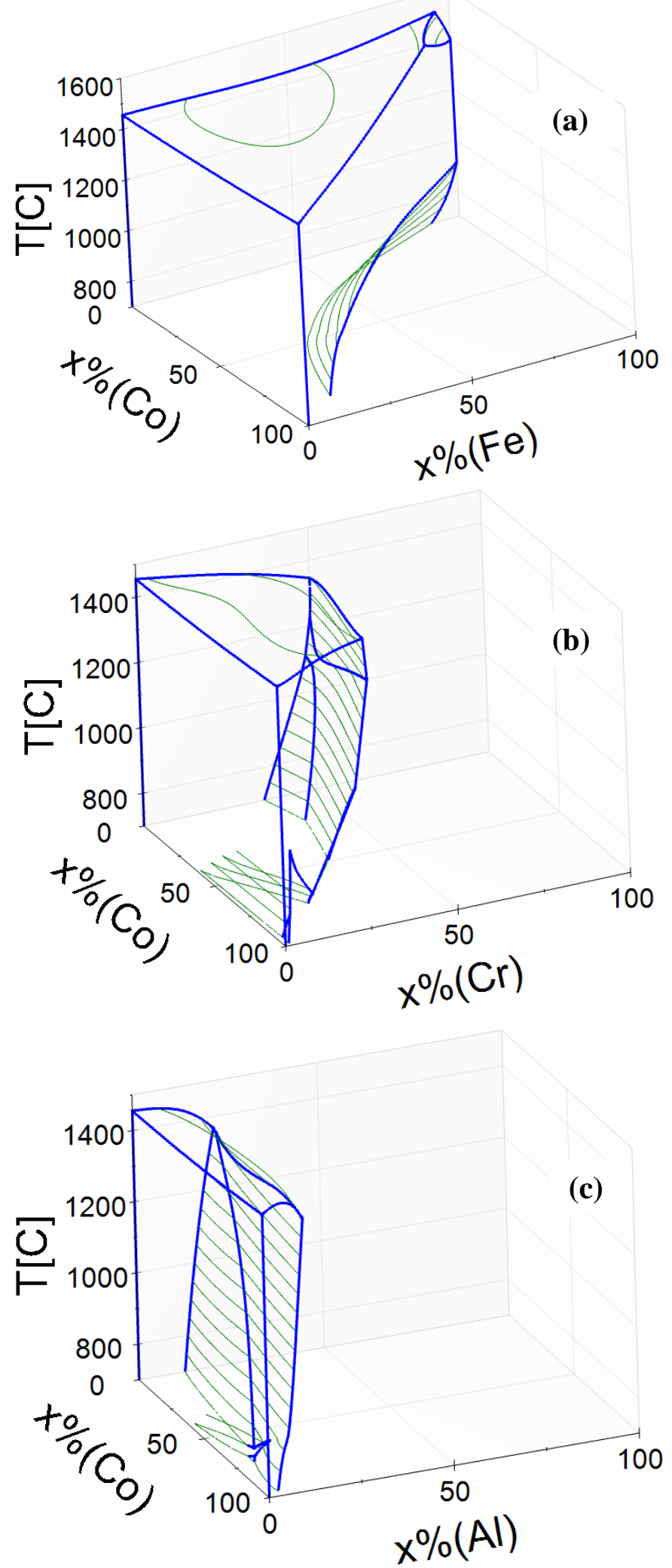

Figure 3: 3D phase projection of the Fcc_A1 phase within constituent ternaries of the Al-Co-Cr-Fe-Ni system (a) $\mathrm{Co}-\mathrm{Ni}-\mathrm{Fe}$; (b) $\mathrm{Co}-\mathrm{Ni}-\mathrm{Cr}$; (c) $\mathrm{Co}-\mathrm{Ni}-\mathrm{Al}$ 

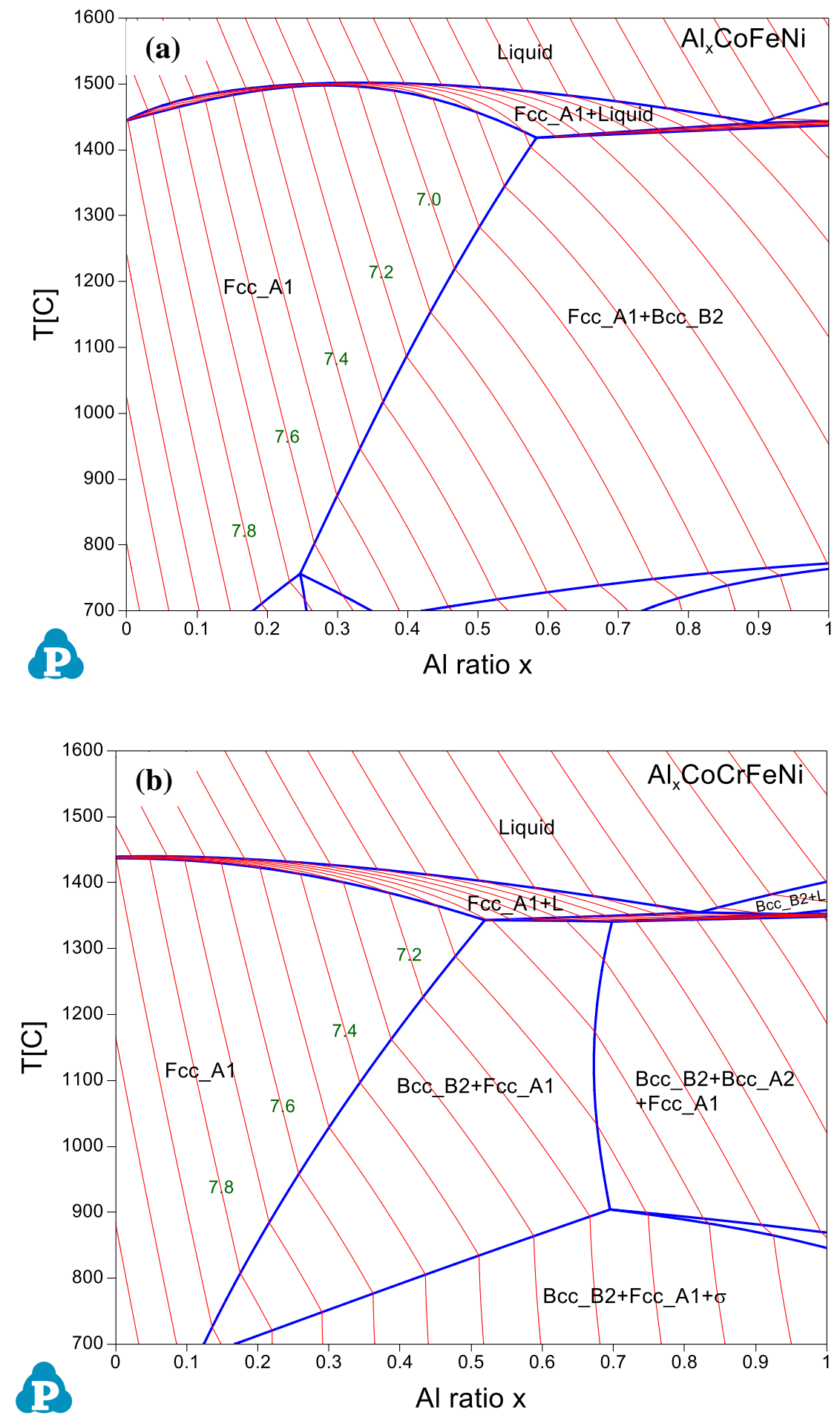

Figure 4: Calculated isopleths with density contour $\left(\mathrm{g} / \mathrm{cm}^{3}\right)$

(a) $\mathrm{Al}_{x} \mathrm{CoFeNi}$; (b) $\mathrm{Al}_{x} \mathrm{CoCrFeNi}$ 

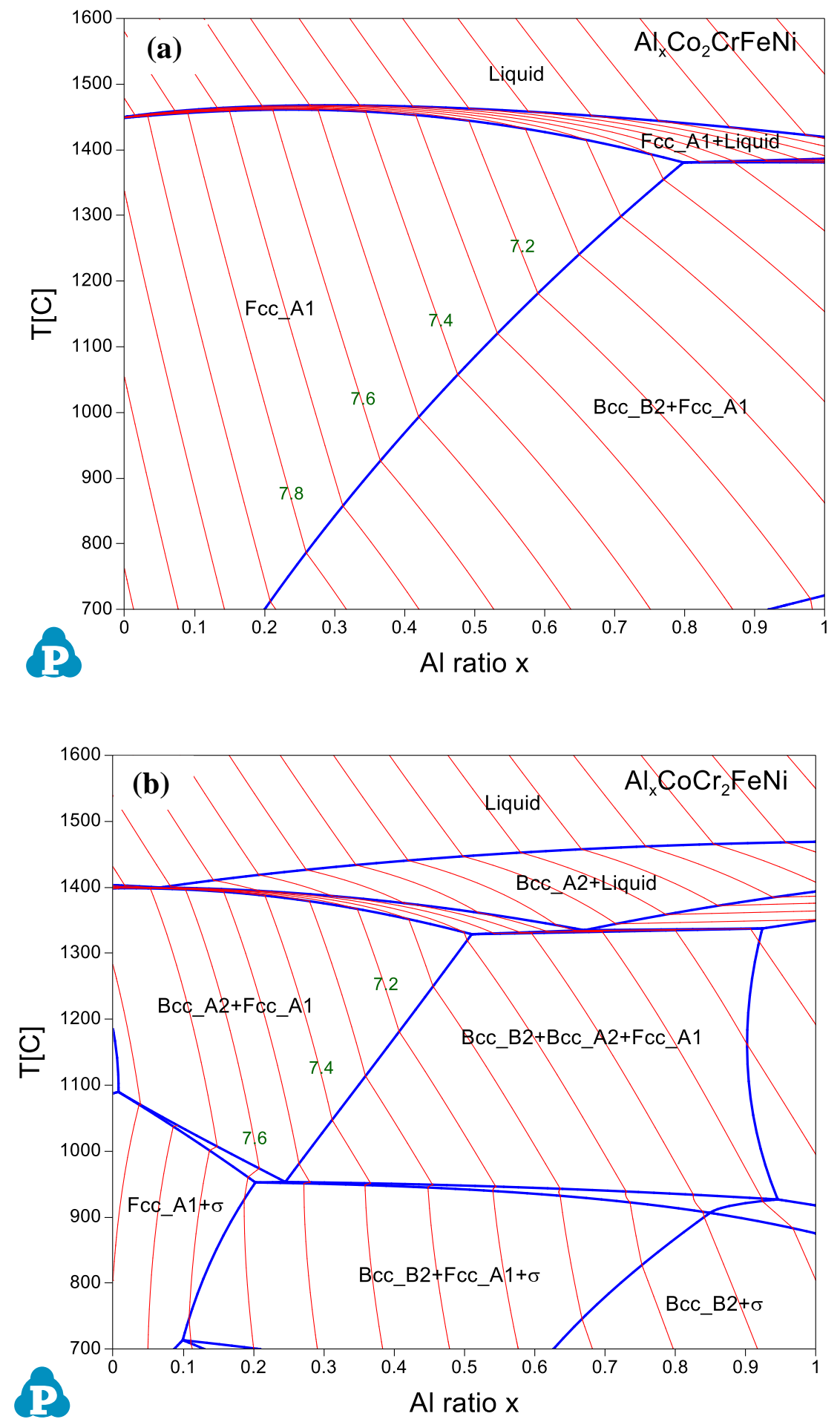

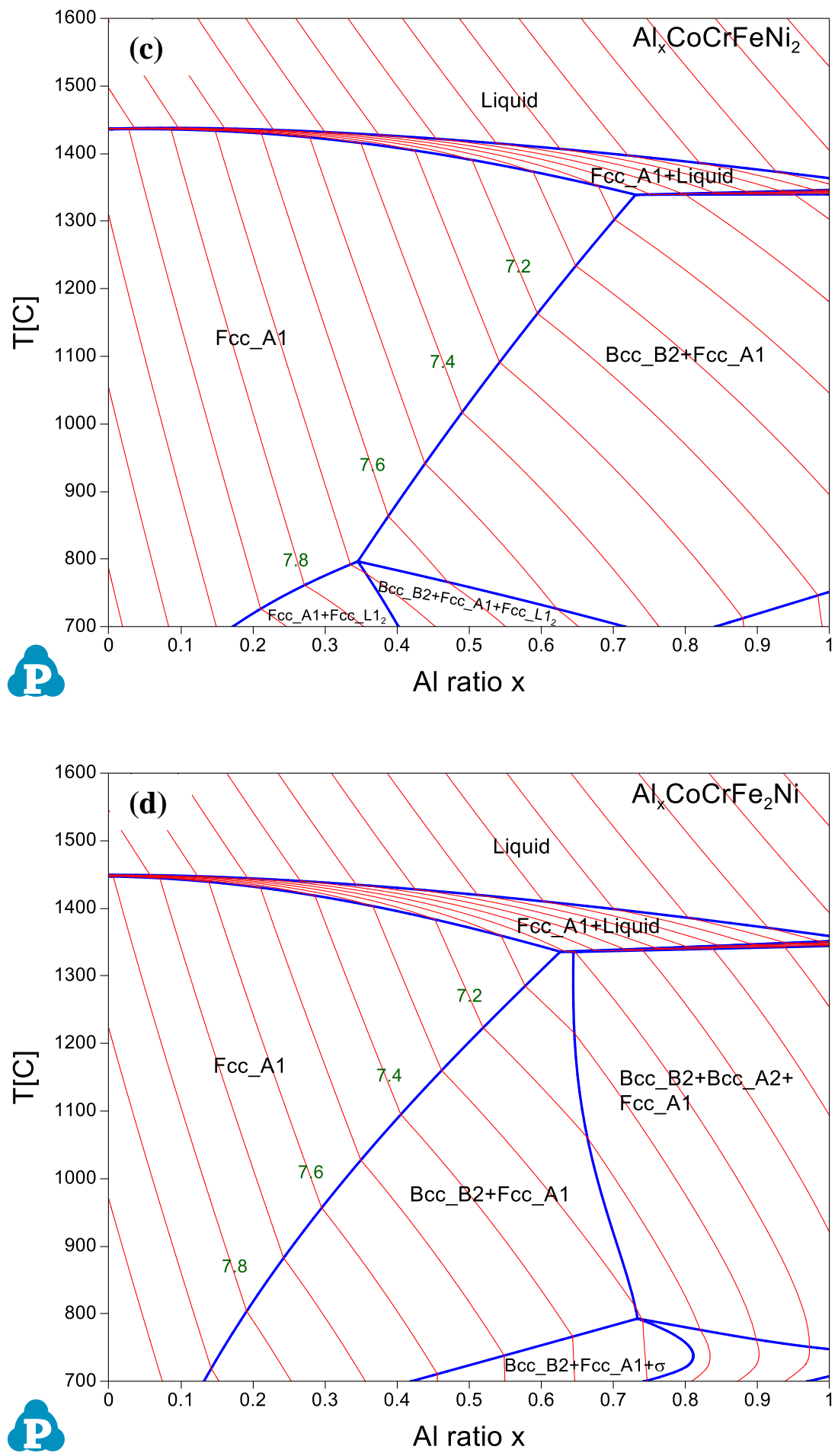

Figure 5: Calculated isopleths with density contour $\left(\mathrm{g} / \mathrm{cm}^{3}\right)$ (a) $\mathrm{Al}_{\mathrm{x}} \mathrm{Co}_{2} \mathrm{CrFeNi}$; (b) $\mathrm{Al}_{\mathrm{x}} \mathrm{CoCr}_{2} \mathrm{FeNi}$; (c) $\mathrm{Al}_{\mathrm{x}} \mathrm{CoCrFeNi}_{2}$; (d) $\mathrm{Al}_{\mathrm{x}} \mathrm{CoCrFe}_{2} \mathrm{Ni}$ 

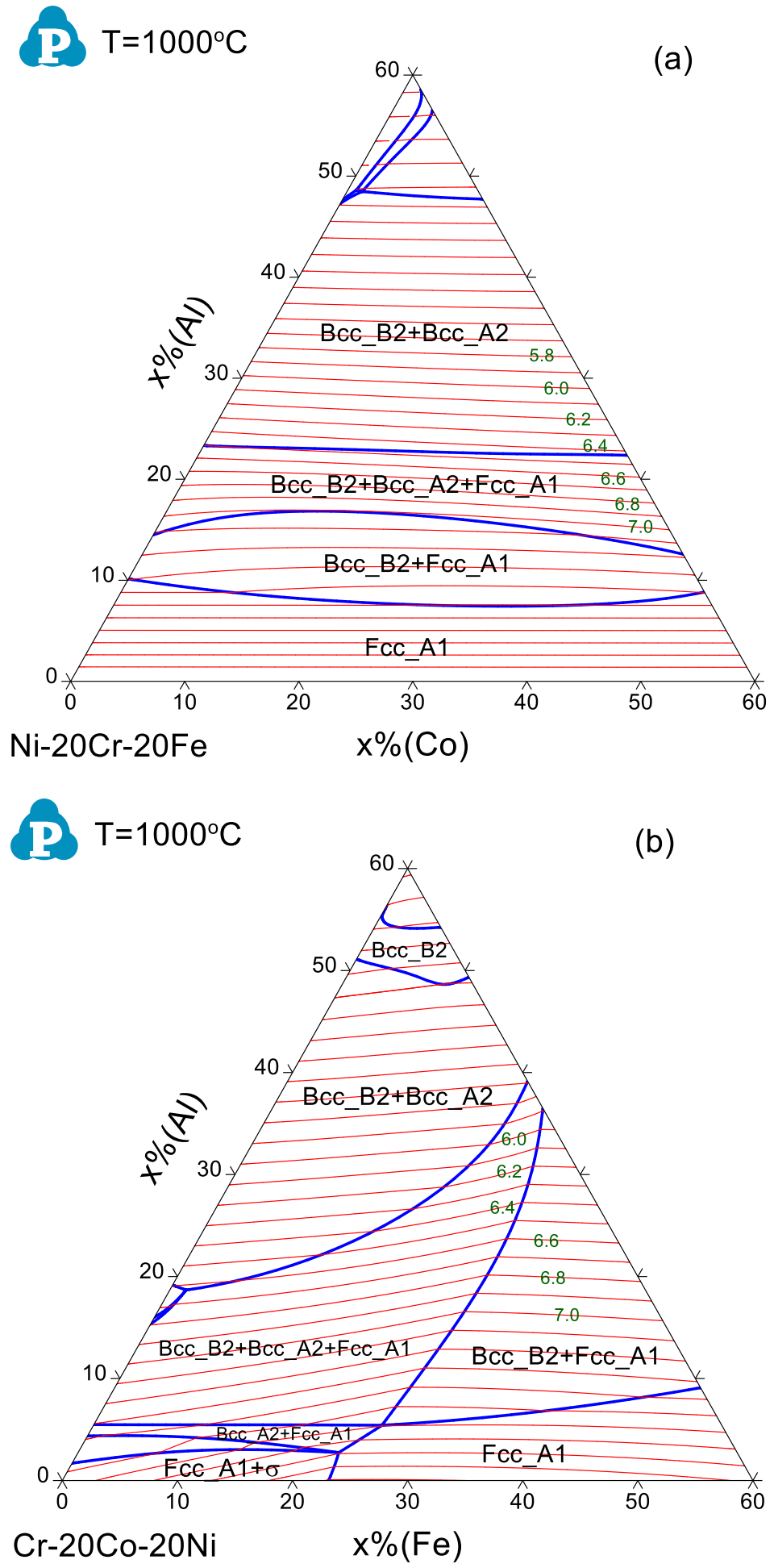

Figure 6: Calculated isothermal sections at $1000{ }^{\circ} \mathrm{C}$ coupled with density contours (red lines, $\mathrm{g} / \mathrm{cm}^{3}$ ) (a) Al-Co-Ni-20Cr-20Fe; (b) Al-Cr-Fe-20Co-20Ni (at.\%) 


\section{References:}

1. J.W. Yeh, S.K. Chen, S.J. Lin, J.Y. Gan, T.S. Chin, T.T. Shun, C.H. Tsau and S.Y. Chang, Nanostructured HighEntropy Alloys with Multiple Principal Elements: Novel Alloy Design Concepts and Outcomes. Advanced Engineering Materials, 2004. 6: p. 299-303.

2. Y.F. Kao, T.J. Chen, S.K. Chen and J.W. Yeh, Microstructure and mechanical property of as-cast, -homogenized, and-deformed AlxCoCrFeNi ( $0 \leq x \leq 2)$ high-entropy alloys. Journal of Alloys and Compounds, 2009. 488: p. 57-64.

3. H.P. Chou, Y.S. Chang, S.K. Chen and J.W. Yeh, Microstructure, thermophysical and electrical properties in AlxCoCrFeNi $(0 \leq x \leq 2)$ high-entropy alloys. Materials Science and Engineering B, 2009. 163: p. 184-189.

4. T.T. Shun and Y.C. Du, Microstructure and tensile behaviors of FCC Al $l_{0.3} \mathrm{CoCrFeNi}$ high entropy alloy. Journal of Alloys and Compounds, 2009. 479: p. 157-160.

5. F.J. Wang, Y. Zhang and G.L. Chen, Cooling Rate and Size Effect on the Microstructure and Mechanical Properties of AlCoCrFeNi High Entropy Alloy. Journal of Engineering Materials and Technology, 2009. 131: p. 034501.

6. C.M. Lin and H.L. Tsai, Evolution of microstructure, hardness, and corrosion properties of high-entropy Al0.5CoCrFeNi alloy. Intermetallics, 2011. 19(3): p. 288-294.

7. Y.F. Kao, S.K. Chen, T.J. Chen, P.C. Chu, J.W. Yeh and S.J. Lin, Electrical, magnetic, and Hall properties of AlxCoCrFeNi high-entropy alloys. Journal of Alloys and Compounds, 2011. 509: p. 1607-1614.

8. W. Chen, Z. Fu, S. Fang, H. Xiao and D. Zhu, Alloying behavior, microstructure and mechanical properties in a $\mathrm{FeNiCrCo}{ }_{0.3} \mathrm{Al}_{0.7}$ high entropy alloy. Materials and Design, 2013. 51: p. 854-860.

9. W.R. Wang, W.L. Wang and J.W. Yeh, Phases, microstructure and mechanical properties of AlxCoCrFeNi highentropy alloys at elevated temperatures. J Alloys Compd., 2014. 589: p. 143-152.

10. Y.-x. Liu, C.-q. Cheng, J.-l. Shang, R. Wang, P. Li and J. Zhao, Oxidation behavior of high-entropy alloys Alx CoCrFeNi $(x=0.15,0.4)$ in supercritical water and comparison with HR3C steel. Trans. Nonferrous Met. Soc. China, 2015. 25.

11. J. Joseph, TomJarvis, XinhuaWu, NicoleStanford, PeterHodgson and D. MarkFabijanic, Comparative study of the microstructures and mechanical properties of direct laser fabricated and arc-melted AlxCoCrFeNi high entropy alloys. Materials Science \& Engineering A, 2015. 633: p. 184-193.

12. H.R. Sistla, J.W. Newkirk and F. Liou, Effect of Al/Ni ratio, heat treatment on phase transformations and microstructure of AlxFeCoCrNi2x ( $x=0.3,1)$ high entropy alloys. Materials and Design, 2015. 81: p. 113-121.

13. T. Yang, S. Xia, S. Liu, C. Wang, S. Liu, Y. Zhang, J. Xue, S. Yan and Y. Wang, Effects of Al addition on microstructure and mechanical properties of AlxCoCrFeNi High-entropy alloy. Materials Science \& Engineering A, 2015. 648: p. 15-22.

14. Z. Fu, W. Chen, H. Wen, Z. Chen and E.J. Lavernia, Effects of Co and sintering method on microstructure and mechanical behavior of a high-entropy $\mathrm{Al}_{0.6} \mathrm{NiFeCrCo}$ alloy prepared by powder metallurgy. Journal of Alloys and Compounds, 2015. 646: p. 175-182.

15. Z. Chen, W. Chen, B. Wu, X. Cao, L. Liu and Z. Fu, Effects of Co and Ti on microstructure and mechanical behavior of $\mathrm{Al}_{0.75} \mathrm{FeNiCrCo}$ high entropy alloy prepared by mechanical alloying and spark plasma sintering. Materials Science \& Engineering A, 2015. 648: p. 217-224.

16. C. Chen, S. Pang, Y. Cheng and T. Zhang, Microstructure and mechanical properties of $A l_{20-}$ ${ }_{x} \mathrm{Cr}_{20+0.5 x} \mathrm{Fe}_{20} \mathrm{Co}_{20} \mathrm{Ni}_{20+0.5 x}$ high entropy alloys. Journal of Alloys and Compounds, 2016. 659: p. 279-287.

17. K. Jasiewicz, J. Cieslak, S. Kaprzyk and J. Tobola, Relative crystal stability of AlxFeNiCrCo high entropy alloys from XRD analysis and formation energy calculation. Journal of Alloys and Compounds, 2015. 648: p. 307-312.

18. T. Cao, J. Shang, J. Zhao, C. Cheng, R. Wang and H. Wang, The influence of Al elements on the structure and the creep behavior of AlxCoCrFeN ihigh entropy alloys. MaterialsLetters, 2016. 164: p. 344-347.

19. Z. Tang, M.C. Gao, H.Y. Diao, T. Yang, J. Liu, T. Zuo, Y. Zhang, Z. Lu, Y. Cheng, Y. Zhang, K.A. Dahmen, P.K. Liaw and T. Egami, Aluminum Alloying Effects on Lattice Types, Microstructures, and Mechanical Behavior of High-Entropy Alloys Systems. JOM, 2013. 65(12): p. 1848-1858.

20. N. Kumar, Q. Ying, X. Nie, R.S. Mishra, Z. Tang, P.K. Liaw, R.E. Brennan, K.J. Doherty and K.C. Cho, High strain-rate compressive deformation behavior of the $\mathrm{Al}_{0.1} \mathrm{CrFeCoNi}$ high entropy alloy. Materials \& Design, 2015. 86(5): p. 598-602.

21. Q. Tang, Y. Huang, H. Cheng, X. Liao, T.G. Langdon and P. Dai, The effect of grain size on the annealing-induced phase transformation in an $\mathrm{Al}_{0.3} \mathrm{CoCrFeNi}$ high entropy alloy. Materials \& Design, 2016. 105(5): p. 381-385. 
22. S.Q. Xia, X. Yang, T.F. Yang, S. Liu and Y. Zhang, Irradiation Resistance in AlxCoCrFeNi High Entropy Alloys. JOM, 2015. 67(10): p. 2340-2344.

23. L. Kaufman and H. Bernstein, Computer Calculation of Phase Diagrams. 1970, Academic Press: New York.

24. M. Hillert, Phase Transformations. 1968, Cleveland, OH: ASM.

25. Y.A. Chang, S.L. Chen, F. Zhang, X.Y. Yan, F.Y. Xie, R. Schmid-Fetzer and W.A. Oates, Phase diagram calculation: past, present and future. Progress in Materials Science, 2004. 49: p. 313-345.

26. Y.A. Chang, Phase diagram calculations in teaching, research, and industry. Metall. Trans. B, 2006. 37B: p. 7-39.

27. C. Zhang, F. Zhang, S. Chen and W. Cao, Computational Thermodynamics Aided High-Entropy Alloy Design. JOM, 2012. 64(7): p. 839-845.

28. C. Zhang and M.C. Gao, CALPHAD Modeling of High-Entropy Alloys, in High-Entropy Alloys - Fundamentals and Applications, M.C. Gao, et al., Editors. 2016, Springer International Publishing: Switzerland. p. 536.

29. M.C. Gao and D.E. Alman, Searching for Next Single-Phase High-Entropy Alloy Compositions. Entropy, 2013. 15: p. 4504-4519.

30. D.B. Miracle, J.D. Miller, O.N. Senkov, C. Woodward, M.D. Uchic and J. Tiley, Exploration and Development of High Entropy Alloys for Structural Applications. Entropy, 2014. 16(1): p. 494-525.

31. F. Zhang, C. Zhang, S.L. Chen, J. Zhu, W.S. Cao and U.R. Kattner, An understanding of high entropy alloys from phase diagram calculations. CALPHAD, 2014. 45: p. 1-10.

32. D.C. Ma, M.J. Yao, K.G. Pradeep, C.C. Tasan, H. Springer and D. Raabe, Phase stability of non-equiatomic CoCrFeMnNi high entropy alloys. Acta Materialia, 2015. 98(1): p. 288-296.

33. $\quad$ Pandat $^{\mathrm{TM}}$, Thermodynamic Calculations and Kinetic Simulations. CompuTherm LLC: Madison, WI - 53719.

34. Z. Tang, O.N. Senkov, C.M. Parish, C. Zhang, F. Zhang, L.J. Santodonato, G.Y. Wang, G.F. Zhao, F.Q. Yang and P.K. Liaw, Tensile ductility of an AlCoCrFeNi multi-phase high-entropy alloy through hot isostatic pressing (HIP) and homogenization. Materials Science and Engineering A, 2015. 647: p. 229-240.

35. L.J. Santodonato, Y. Zhang, M. Feygenson, C.M. Parish, M.C. Gao, R.J.K. Weber, J.C. Neuefeind, Z. Tang and P.K. Liaw, Deviation from high-entropy configurations in the atomic distributions of a multi-principal-element alloy. Nature Communications, 2015. 6: p. 5964.

36. X.G. Lu, M. Selleby and B. Sundman, Assessments of molar volume and thermal expansion for selected bcc, fcc and hep metallic elements. Calphad, 2005. 29: p. 68-89.

37. O. Redlich and A.T. Kister, Algebraic Representation of Thermodynamic Properties and the Classification of Solutions. Ind. Eng. Chem., 1948. 40: p. 345-348.

38. F. Zhang, W. Cao, S.L. Chen, C. Zhang and J. Zhu, The Role of the CALPHAD Approach in ICME, in $2^{\text {nd }}$ World Congress on Integrated Computational Materials Engineering, M. Li, et al., Editors. 2013, John Wiley \& Sons, Inc: Hoboken, NJ, USA. p. 195-200. 


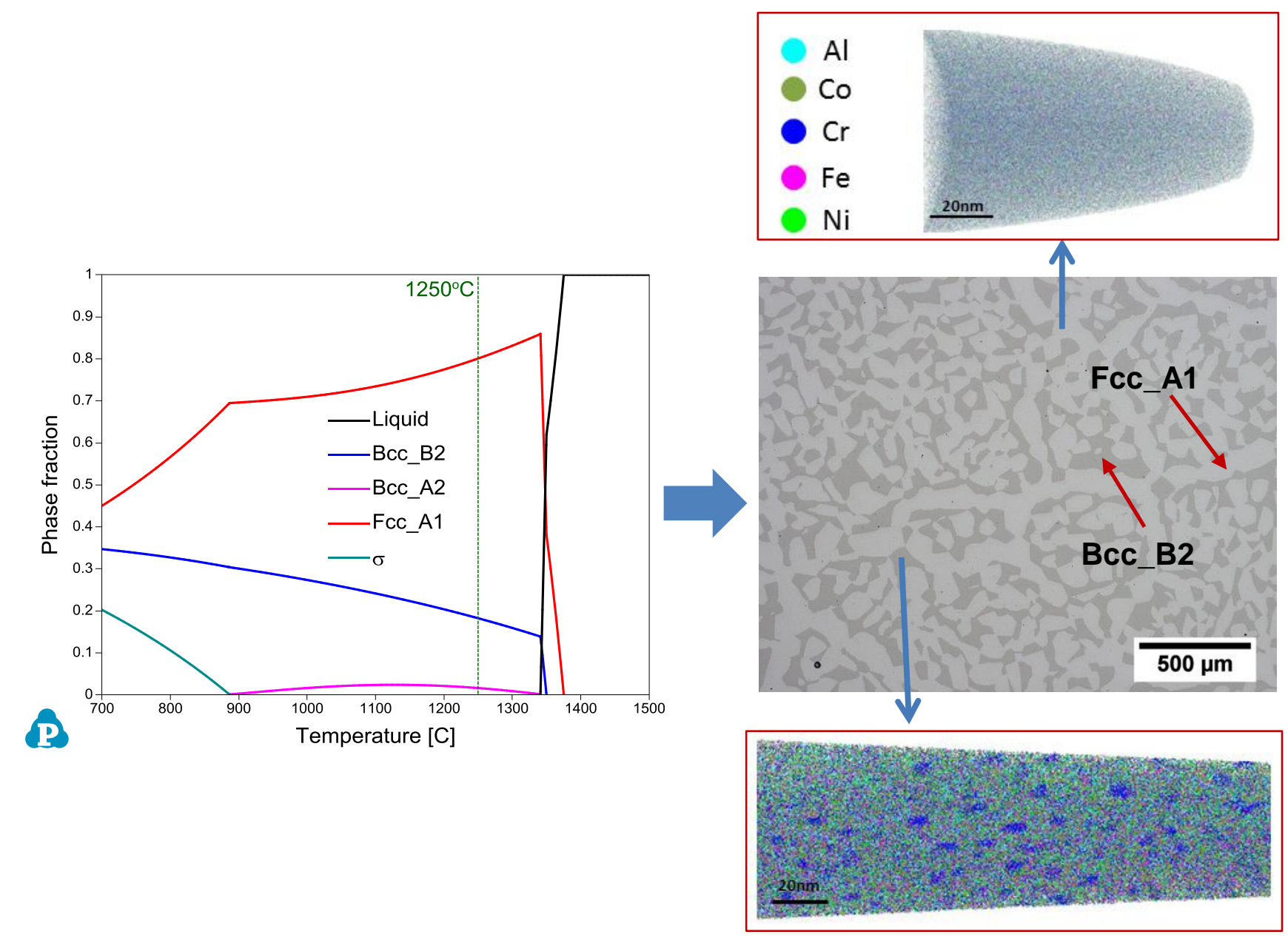

